\title{
TEOR DE NITROGÊNIO SOLÚVEL NA ÁGUA DE EROSÃO HÍDRICA EM CULTURA DE AVEIA E ERVILHACA EM TRÊS FORMAS DE SEMEADURA ${ }^{(1)}$
}

\author{
Fabrício Tondello Barbosa ${ }^{(2)}$, Ildegardis Bertol ${ }^{(3)}$, Rodrigo Vieira \\ Luciano $^{(4)}$, Antonio Paz González ${ }^{(5)}$ \& Eva Vidal Vázquez ${ }^{(6)}$
}

\begin{abstract}
RESUMO
A perda de nutrientes por erosão hídrica causa empobrecimento do solo e reduz a produtividade das culturas, além de causar contaminação da água. $\mathrm{O} N$ solúvel na água de enxurrada é biodisponível, contribui para a eutrofização das águas e, dependendo de sua forma e teor, é tóxico aos organismos aquáticos. Com o objetivo de avaliar os teores de $\mathrm{NH}_{4}{ }^{+} \mathrm{e} \mathrm{NO}_{3}^{-}$na água de enxurrada, realizou-se um experimento com chuva simulada, de abril a novembro de 2006, num Cambissolo Húmico alumínico léptico, com preparo convencional. A combinação de três fatores foi estudada: espécie vegetal (cultura), forma de semeadura e teste de chuva simulada. Avaliaram-se as culturas de aveia-preta (Avena strigosa) e ervilhaca-comum (Vicia sativa). As formas de semeadura foram mecanizada em linhas no sentido da pendente do terreno, a lanço, e mecanizada em linhas em contorno no declive. Foram feitos cinco testes de chuva simulada, com intensidade constante e planejada de $64 \mathrm{~mm} \mathrm{~h}^{-1}$ e duração de uma hora: os quatro primeiros durante o ciclo de desenvolvimento das culturas e o quinto sobre os resíduos culturais mantidos na superfície do solo. A aplicação de $\mathrm{N}$ na forma de uréia em cobertura na aveia imediatamente antes da aplicação do primeiro teste de chuva resultou em maior teor de $\mathrm{N}^{-\mathrm{NH}_{4}}{ }^{+}$na água de enxurrada, do que naquela proveniente do cultivo de ervilhaca, superando os teores aceitáveis para a comunidade aquática. O teor de $\mathrm{N}_{-} \mathrm{NO}_{3}{ }^{-}$na água de enxurrada foi maior na semeadura em contorno do que na pendente na presença de resíduos vegetais em decomposição na superfície do solo. Os teores de $\mathrm{N}-\mathrm{NH}_{4}{ }^{+}$e $\mathrm{N}-\mathrm{NO}_{3}{ }^{-}$na água de
\end{abstract}

\footnotetext{
(1) Parte da Dissertação de Mestrado do primeiro autor. Recebido para publicação em julho de 2007 e aprovado em fevereiro de 2009.

(2) Mestrando do Departamento de Solos do Centro de Ciências Agroveterinárias, Universidade do Estado de Santa Catarina CAV/UDESC. CEP 88520-000 Lages (SC). Bolsista CAPES. E-mail: a6ftb@cav.udesc.br

${ }^{(3)}$ Professor do Departamento de Solos do Centro de Ciências Agroveterinárias, CAV/UDESC. Bolsista PQ CNPq. E-mail: a2ib@cav.udesc.br

(4) Mestrando do Departamento de Solos, CAV/UDESC. Bolsista (CNPq). E-mail: agro.luciano@gmail.com

(5) Professor da Universidade de Coruña, La Coruña, Espanha. E-mails: tucho@udc.es; evavidal@mail2.udc.es
} 
enxurrada diminuíram ao longo do ciclo das culturas, aumentando no teste realizado sobre os resíduos culturais da ervilhaca, onde os referidos teores foram maiores do que sobre os resíduos de aveia.

Termos de indexação: nitrogênio na enxurrada, cultivo em contorno, chuva simulada, planta de cobertura.

\title{
SUMMARY: SOLUBLE NITROGEN CONTENT IN RUNOFF WATER FROM THREE FORMS OF OAT AND VETCH SOWING
}

\begin{abstract}
Where nutrients are lost by water erosion the eroded soil is impoverished and crop productivity is reduced, apart from the water contamination. Soluble $N$ in the runoff is biologically available and contributes to eutrophication of the water and, depending on the form and content in the water, may be toxic to aquatic organisms. In order to evaluate the $N$ content in the form of ammonium and nitrate in the runoff water, an experiment was conducted with simulated rainfall from April to November 2006, on an Inceptisol under conventional tillage. A combination of three factors was studied: crop type, sowing form and simulated rainfall test. The crops black oat (Avena strigosa) and common vetch (Vicia sativa) were studied, as well as the sowing forms: mechanical, along rows in slope direction; broadcast by hand; and mechanized along contour lines; and five simulated rainfall tests, at a constant and planned intensity of $64 \mathrm{~mm} \mathrm{~h}^{-1}$ and rainfall duration of $1 \mathrm{~h}$. The first four rainfall tests were applied during the crop cycles and the fifth on the crop residues maintained on the soil surface. Nitrogen application to oat as urea cover dressing, immediately before rainfall test 1, resulted in a higher $\mathrm{N}-\mathrm{NH}_{4}^{+}$content in the runoff water from oat than from vetch, exceeding the acceptable level for the aquatic community. Under rainfall on residues in decomposition on the soil surface, the content of soluble $\mathrm{N}-\mathrm{NO}_{3}{ }^{-}$in the runoff water was higher in the crops of contour sowing than of slope sowing. The contents of soluble $\mathrm{N}-\mathrm{NH}_{4}{ }^{+}$and $\mathrm{N}-\mathrm{NO}_{3}{ }^{-}$in the runoff water decreased from the beginning to the end of the crop cycles, but increased in the rainfall test on vetch mulch, to higher values than in the treatment with oat residue.
\end{abstract}

Index terms: nitrogen in runoff water, contour cropping, simulated rainfall, cover crop.

\section{INTRODUÇÃO}

Nutrientes perdidos por erosão hídrica empobrecem o solo e reduzem a produtividade das culturas (Schick et al., 2000; Bertol et al., 2004), além de contaminarem as águas (Alberts et al., 1978). O N solúvel é mais prontamente biodisponível que as formas de $\mathrm{N}$ ligadas aos sedimentos (McIsaac et al., 1995) e contribui para a eutrofização das águas em mananciais (Pote et al., 1996).

$\mathrm{O}$ teor de um elemento na água de enxurrada depende do seu teor no solo, sendo influenciado pelo preparo, pela cobertura e manejo do solo, pelas fertilizações e pelo volume de chuvas (Seganfredo et al., 1997; Schick et al., 2000).

$\mathrm{Na}$ maioria dos sistemas de manejo do solo, os maiores teores de nutrientes perdidos na enxurrada ocorrem na fase inicial do ciclo das culturas (Leite, 2003). Bertol et al. (2003) observaram teores maiores de N na água de enxurrada no primeiro teste de chuva simulada realizado em cultivo de solo, diminuindo nos subsequentes. Por sua vez, Aita \& Giacomini (2003), estudando a liberação de $\mathrm{N}$ pela decomposição de resíduos culturais, observaram maior velocidade de decomposição do resíduo de ervilhaca e liberação do elemento relativamente ao resíduo de aveia. Isso é um indicativo de que a cultura pode alterar os teores de $\mathrm{N}$ na água de enxurrada.

No cultivo em contorno, o preparo do solo e a semeadura, a rugosidade orientada formada pelas marcas dos implementos e a disposição das plantas, opostas ao sentido do declive aumentam o armazenamento e a infiltração de água no solo. Além disso, filtram os sedimentos, retardam o início da enxurrada e reduzem o volume de escoamento superficial e as perdas de solo (Bertoni \& Lombardi Neto, 2005). Isso pode alterar o comportamento dos nutrientes perdidos por erosão em relação ao preparo do solo e à semeadura feitos no sentido do declive (Barbosa, 2008). A rugosidade ao acaso, caracterizada pela ocorrência aleatória de microelevações e microdepressões na superfície do solo, também reduz 
as perdas de solo e água, pois aumenta a retenção superficial da água da chuva (Barbosa, 2008; Luciano, 2008), podendo alterar as perdas de nutrientes por erosão hídrica. Quando o preparo do solo é feito no sentido do declive, o processo erosivo é acelerado, pois os sulcos e as linhas das culturas formam corredores, por onde a água desce livremente e adquire velocidade suficiente para causar erosão, também devido à baixa infiltração no solo (Pires \& Souza, 2003).

O objetivo deste trabalho foi determinar os teores de $\mathrm{NH}_{4}{ }^{+}$e $\mathrm{NO}_{3}{ }^{-}$na água de enxurrada, ocasionada por chuvas simuladas, em três formas de semeadura, nas culturas de aveia-preta e ervilhaca-comum.

\section{MATERIAL E MÉTODOS}

O experimento foi realizado em campo, entre abril e novembro de 2006, com chuva simulada, em local situado entre as coordenadas $27^{\circ} 49^{\prime}$ latitude sul e $50^{\circ} 20^{\prime}$ longitude oeste de Greenwich, a $900 \mathrm{~m}$ de altitude média, no sul do Brasil. O clima é do tipo $\mathrm{Cfb}$ - subtropical úmido (Köeppen) e o solo é um Cambissolo Húmico alumínico léptico horizonte A moderado, com substrato composto de siltitos e argilitos.

O solo no local do experimento estava coberto com campo natural até março de 2006, quando se fez a correção da acidez do solo com a incorporação de $15 \mathrm{t} \mathrm{ha}^{-1}$ de calcário dolomítico $(\mathrm{PRNT}=80 \%)$, por meio de arações e gradagens. Em maio de 2006, foi instalado o experimento, e o preparo do solo consistiu em uma aração e duas gradagens. Avaliou-se a combinação de três fatores: cultura, forma de semeadura e teste de chuva simulada. As culturas avaliadas foram aveia-preta (Avena strigosa) e ervilhaca-comum (Vicia sativa). As formas de semeadura foram mecanizada em linhas no sentido paralelo ao declive, a lanço sendo as sementes incorporadas ao solo com rastelo, e mecanizada em linhas em contorno no declive. Foram feitos cinco testes de chuva simulada, com intensidade constante e planejada de $64 \mathrm{~mm} \mathrm{~h}^{-1}$ e duração de uma hora cada um: quatro durante o ciclo de desenvolvimento das culturas, e o último sobre os resíduos culturais deitados na superfície do solo. O primeiro teste de chuva foi realizado no início do ciclo das culturas, 30 dias após a semeadura, e os demais aos 70, 104, 108 e 140 dias após a semeadura. As culturas estavam em pleno crescimento vegetativo quando da realização do segundo teste. Já no terceiro e quarto testes, as culturas estavam em início de florescimento. O último teste foi feito 10 dias após as culturas terem sido roçadas e os resíduos deitados no solo. A semeadura mecanizada das culturas (na pendente e em contorno) foi realizada com semeadora de parcelas experimentais acoplada a um trator, com regulagem da profundidade das sementes de $4 \mathrm{~cm}$, formando sulcos no solo, na direção da linha da semeadora. O espaçamento entre linhas foi de $0,20 \mathrm{~m}$. Na semeadura a lanço, as sementes foram distribuídas manualmente e incorporadas ao solo com rastelo. As quantidades de sementes utilizadas foram: $100 \mathrm{~kg} \mathrm{ha}^{-1}$, de aveia-preta e $60 \mathrm{~kg} \mathrm{ha}^{-1}$, de ervilhaca-comum. As culturas receberam adubações distintas, seguindo as recomendações técnicas da Comissão (SBCS, 2004). Os adubos foram incorporados ao solo um dia antes da semeadura das culturas, por meio de uma gradagem leve. Foram aplicados $60 \mathrm{~kg} \mathrm{ha}^{-1} \mathrm{de}_{2} \mathrm{O}_{5}$ e $70 \mathrm{~kg} \mathrm{ha}^{-1} \mathrm{de}_{2} \mathrm{O}$ na ervilhaca-comum; na aveiapreta aplicou-se $70 \mathrm{~kg} \mathrm{ha}^{-1}$ de $\mathrm{P}_{2} \mathrm{O}_{5}$ e $70 \mathrm{~kg} \mathrm{ha}^{-1} \mathrm{de}$ $\mathrm{K}_{2} \mathrm{O}$, na forma de superfosfato triplo e cloreto de potássio, respectivamente. As sementes de ervilhaca foram inoculadas com Rhizobium específico. Nos tratamentos com aveia, foram aplicados $20 \mathrm{~kg} \mathrm{ha}^{-1} \mathrm{de}$ $\mathrm{N}$ em cobertura, na forma de uréia, imediatamente antes do primeiro teste de chuva simulada, que correspondeu ao estádio de perfilhamento da aveia. Em novembro de 2006, no período de enchimento de grãos, as culturas foram roçadas com roçadora costal e o resíduo vegetal foi distribuído uniformemente e deitado sobre o solo.

As unidades experimentais, em duplicata, com dimensões de 3,5 m de largura e $11 \mathrm{~m}$ de comprimento $\left(38,5 \mathrm{~m}^{2}\right)$, foram instaladas conforme indicações de Bertol et al. (1987). Para a realização das chuvas simuladas, utilizou-se um aparelho simulador de chuva de braços rotativos que cobria simultaneamente duas parcelas (Swanson, 1975).

Imediatamente antes de cada teste de chuva simulada, foram coletadas subamostras do solo na profundidade de $0-2,5 \mathrm{~cm}$, em três pontos das parcelas experimentais, as quais, após homogeneização, compuseram única amostra para posterior determinação dos teores de $\mathrm{N}$ mineral no solo. A coleta de amostras para a determinação do teor de $\mathrm{N}$ na água de enxurrada foi feita em intervalos de $10 \mathrm{~min}$, a partir do início da enxurrada. Também foram coletadas amostras da água do açude, que era utilizada e bombeada para o simulador para produzir as chuvas simuladas. As amostras coletadas na água de enxurrada e do açude foram congeladas e posteriormente filtradas em papel-filtro de $8,0 \mu \mathrm{m}$ de diâmetro dos poros. Os teores de $\mathrm{N}$ mineral $\left(\mathrm{N}_{-} \mathrm{NH}_{4}{ }^{+}\right.$ e N- $\mathrm{NO}_{3}{ }^{-}$) do solo na camada de $0-2,5 \mathrm{~cm}$ foram determinados utilizando-se o método descrito por Bremner \& Keeney (1966). Os teores de $\mathrm{N}^{-\mathrm{NH}_{4}{ }^{+} \mathrm{e}}$ $\mathrm{N}-\mathrm{NO}_{3}{ }^{-}$na água de enxurrada foram determinados por meio de destilação direta do material, pelo método de Bremner \& Keeney (1966). Os teores na água de enxurrada foram determinados individualmente em cada coleta e o valor correspondente por parcela foi obtido por uma média, subtraindo-se desses valores o valor do teor do elemento contido na água do açude.

Os dados foram submetidos à análise de variância, utilizando-se o teste F, a $5 \%$. Quando encontrada significância estatística, a diferença entre duas médias foi conclusiva pelo teste $\mathrm{F}$. O teste de Tukey a $5 \%$ foi 
utilizado para a comparação de mais de duas médias de tratamentos. Os modelos $\mathrm{y}=\mathrm{a} \mathrm{e}^{-\mathrm{bx}}, \mathrm{y}=\mathrm{a} \mathrm{x}^{-\mathrm{b}}$ e $\mathrm{y}=$ $\mathrm{a}+\mathrm{b} \mathrm{x}$ foram utilizados para relacionar os valores dos teores de $\mathrm{N}-\mathrm{NH}_{4}{ }^{+}$e N-NO${ }_{3}{ }^{-}$com os de quantidade de chuva, enquanto o modelo $\mathrm{y}=\mathrm{a} \mathrm{x}^{-\mathrm{b}}$ foi utilizado para relacionar os valores de $\mathrm{N}$ mineral solúvel na água de enxurrada com os de $\mathrm{N}$ mineral na camada superficial do solo.

\section{RESULTADOS E DISCUSSÃO}

\section{Teor de $\mathrm{N}-\mathrm{NH}_{4}{ }^{+}$solúvel na água de enxurrada}

O teor de $\mathrm{N}-\mathrm{NH}_{4}{ }^{+}$na água de enxurrada foi significativamente influenciado pelo efeito do teste de chuva e pela interação entre cultura e teste de chuva. Com isso, houve o interesse em comparar os testes de chuva em cada cultura e, também, comparar as culturas em cada teste de chuva.

Nos testes de chuva simulada, o teor de $\mathrm{N}-\mathrm{NH}_{4}{ }^{+}$ foi significativamente maior no início do ciclo das culturas (teste 1) do que ao longo do cultivo (testes 2 a 4), em ambas as culturas (Quadro 1). Esse comportamento assemelha-se aos obtidos por Leite (2003), que, avaliando tratamentos de manejo do solo nas culturas de milho e feijão sob chuva simulada, encontrou maiores teores de $\mathrm{NH}_{4}{ }^{+}$na água de enxurrada no primeiro teste de chuva realizado logo após a semeadura das culturas, diminuindo nos testes subsequentes. $\mathrm{O}$ teor de $\mathrm{N}-\mathrm{NH}_{4}{ }^{+}$na água de enxurrada proveniente da área cultivada com aveia no segundo teste de chuva foi equivalente a $4 \%$ daquele verificado no teste anterior, enquanto que para a área cultivada com ervilhaca a equivalência foi de $56 \%$. Ao se relacionar o teor de $\mathrm{N}-\mathrm{NH}_{4}{ }^{+}$na água de enxurrada com a quantidade de chuva acumulada durante o ciclo das culturas (Figura 1), observou-se que, no cultivo de aveia, esse teor decresceu de forma exponencial em resposta ao aumento da quantidade de chuva, com ajuste significativo; já na ervilhaca, decresceu de forma linear, também significativa. A redução do estoque de $\mathrm{N}-\mathrm{NH}_{4}{ }^{+}$no solo, decorrente da absorção pelas plantas, a transformação de $\mathrm{NH}_{4}{ }^{+}$em $\mathrm{NO}_{3}^{-}$e o transporte de $\mathrm{N}$ pela enxurrada de chuvas anteriores no decorrer do período experimental explicam o comportamento decrescente no tempo. Após o início de crescimento das culturas, do segundo ao quarto teste de chuva, o teor de $\mathrm{N}-\mathrm{NH}_{4}{ }^{+}$na água de enxurrada foi baixo e não diferiu estatisticamente entre si, independente da espécie cultivada (Quadro 1). Isso se deve ao fato de que o $\mathrm{NH}_{4}{ }^{+}$é convertido rapidamente a $\mathrm{NO}_{3}{ }^{-}$no solo. Tal efeito também explica, em parte, a redução acentuada do teor de $\mathrm{N}-\mathrm{NH}_{4}{ }^{+}$do primeiro para o segundo teste de chuva, principalmente na área cultivada com aveia, que recebeu a aplicação de uréia. No cultivo de ervilhaca, o teor de $\mathrm{N}-\mathrm{NH}_{4}{ }^{+}$na água de enxurrada proveniente do teste de chuva realizado sobre os resíduos culturais foi significativamente maior ( 6,8 vezes) do que no último teste realizado sobre a cultura (Quadro 1). Na aveia, no entanto, não houve diferença no teor de $\mathrm{N}-\mathrm{NH}_{4}{ }^{+}$na água de enxurrada entre os dois testes de chuva. Isto pode ser atribuído à decomposição mais rápida do resíduo de ervilhaca, liberando $\mathrm{N}$ mais rapidamente e em maior quantidade do que o resíduo de aveia, concordando com Aita \& Giacomini (2003).

$\mathrm{O}$ teor de $\mathrm{N}-\mathrm{NH}_{4}{ }^{+}$na água de enxurrada foi influenciado pela espécie cultivada no início do cultivo (teste 1) e sobre os resíduos culturais (teste 5) mantidos na superfície do solo (Quadro 1). No primeiro teste, a aveia apresentou teor de $\mathrm{N}-\mathrm{NH}_{4}{ }^{+}$na água de enxurrada 3,7 vezes maior do que a ervilhaca, sendo estatisticamente diferente. Este comportamento devese ao fato de que, nos tratamentos com aveia, imediatamente antes da realização deste teste, foi aplicado $\mathrm{N}$ em cobertura na forma de uréia, o que não foi feito nos tratamentos com ervilhaca. A uréia, em contato com a superfície do solo e com a água da chuva, disponibilizou o $\mathrm{N}$ na forma de $\mathrm{NH}_{4}^{+}$, aumentando o seu teor na água de enxurrada no primeiro teste de chuva. No que se refere ao teor de $\mathrm{N}-\mathrm{NH}_{4}{ }^{+}$aceitável para a qualidade das águas, não deve ser superior a $2,5 \mathrm{mg} \mathrm{L} \mathrm{L}^{-1}$ para peixes em geral, conforme Sharpley et al. (1987). No primeiro teste de chuva, o teor de $\mathrm{N}-\mathrm{NH}_{4}{ }^{+}$na água de enxurrada proveniente da área cultivada com aveia, a qual recebeu adubação nitrogenada, superou o teor aceitável em aproximadamente duas vezes (Quadro 1). Com isso, a água escoada superficialmente neste tratamento apresenta risco potencial para prejudicar a comunidade

Quadro 1. Teor de $\mathrm{N}-\mathrm{NH}_{4}^{+}$solúvel na água de enxurrada nas culturas e nos testes de chuva simulada

\begin{tabular}{|c|c|c|c|c|c|}
\hline \multirow{2}{*}{ Cultura } & \multicolumn{5}{|c|}{ Teste de chuva } \\
\hline & Teste 1 & Teste 2 & Teste 3 & Teste 4 & Teste 5 \\
\hline Aveia & $4,85 \mathrm{a}^{*}$ & $0,21 b^{n s}$ & $0,13 b^{\mathrm{ns}}$ & $0,12 \mathrm{~b}^{\mathrm{ns}}$ & $0,48 b^{*}$ \\
\hline Ervilhaca & $1,31 \mathrm{a}$ & $0,73 \mathrm{~b}$ & $0,36 \mathrm{~b}$ & $0,28 \mathrm{~b}$ & $1,90 \mathrm{a}$ \\
\hline
\end{tabular}

Média sucedida por mesma letra minúscula na linha, dentro de cada cultura, não difere significativamente pelo teste de Tukey $(\mathrm{p}<0,05)$. Efeito de cultura, dentro de cada teste: ${ }^{*}$ significativo e ${ }^{\text {ns }}$ não-significativo por análise de variância, utilizando-se o teste $\mathrm{F}(\mathrm{p}<0,05)$. Média das formas de semeadura e das repetições. 


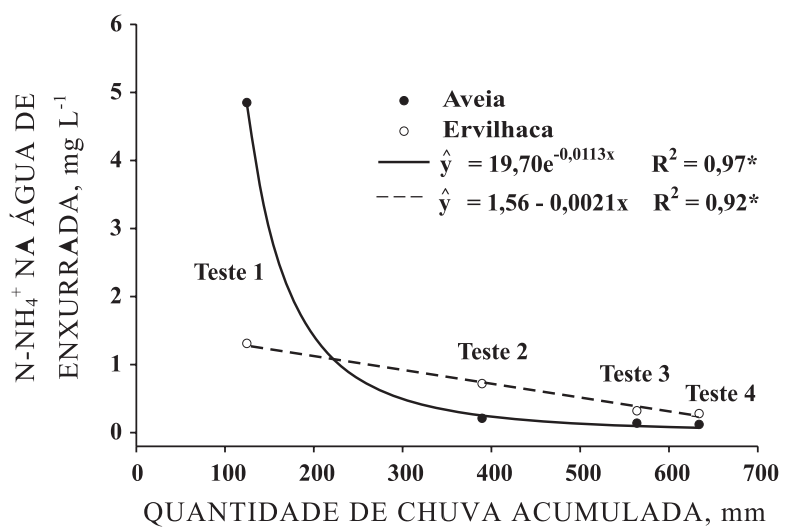

Figura 1. Relação entre o teor de $\mathrm{N}_{-} \mathrm{NH}_{4}{ }^{+}$na água de enxurrada e a quantidade de chuva acumulada (natural e simulada), durante o ciclo das culturas de aveia e ervilhaca (média das formas de semeadura e das repetições).

aquática (principalmente peixes) se tal escoamento encontrar um corpo d'água. Isso é preocupante, pois é prática comum entre os agricultores aplicar este tipo de fertilizante nitrogenado nas lavouras, geralmente em quantidades elevadas, pouco antes da chuva. Nos demais testes de chuva simulada, durante o ciclo das culturas (testes 2 a 4), não houve diferença significativa no teor de $\mathrm{N}-\mathrm{NH}_{4}{ }^{+}$na água da enxurrada entre as culturas (Quadro 1). No quinto teste de chuva, realizado sobre os resíduos vegetais de aveia e ervilhaca deitados na superfície do solo, o teor de $\mathrm{N}-\mathrm{NH}_{4}{ }^{+}$na água de enxurrada diferiu, tendo sido quatro vezes maior nos resíduos de ervilhaca do que nos resíduos de aveia (Quadro 1). Isso demonstra que o resíduo da ervilhaca libera $\mathrm{N}$ em maior quantidade e mais rapidamente do que a aveia.

\section{Teor de $\mathrm{N}-\mathrm{NO}_{3}{ }^{-}$solúvel na água de enxurrada}

$\mathrm{O}$ teor de $\mathrm{N}-\mathrm{NO}_{3}{ }^{-}$na água de enxurrada foi influenciado pelos fatores cultura, forma de semeadura e teste de chuva, bem como pela interação dos fatores cultura com teste de chuva e forma de semeadura com teste de chuva. Na interação entre cultura e teste de chuva (Quadro 2), a comparação foi idêntica à realizada para o $\mathrm{N}-\mathrm{NH}_{4}{ }^{+}$. No caso da interação entre forma de semeadura e teste de chuva (Quadro 3), havia o interesse em apenas comparar as formas de semeadura dentro de cada teste de chuva.

Como ocorreu para o N- $\mathrm{NH}_{4}{ }^{+}$, o teor de $\mathrm{N}-\mathrm{NO}_{3}{ }^{-}$na água de enxurrada foi significativamente maior no início do ciclo das culturas, aumentando, no entanto, no teste de chuva realizado sobre os resíduos culturais em comparação ao último teste realizado durante o cultivo (Quadro 2). Para a aveia, o teor de $\mathrm{N}^{-\mathrm{NO}_{3}}{ }^{-}$na água de enxurrada no segundo teste foi equivalente a $12 \%$ daquele determinado no primeiro teste, enquanto, para a ervilhaca, esta equivalência foi de $46 \%$. A diminuição dos teores de $\mathrm{NO}_{3}{ }^{-}$na água de enxurrada deve-se principalmente à absorção do $\mathrm{N}$ pelas plantas e às perdas do elemento por erosão ao longo do ciclo das culturas. Além disso, provavelmente ocorreu lixiviação de $\mathrm{NO}_{3}{ }^{-}$no perfil, ocasionada pela infiltração de água no solo. Isto acontece porque o íon de $\mathrm{NO}_{3}^{-}$não é adsorvido eletrostaticamente nos minerais do solo. Isso faz com que o $\mathrm{NO}_{3}{ }^{-}$permaneça predominantemente na solução do solo e sujeito à percolação, dependendo da quantidade de água que infiltra, conforme Cantarella (2007). Durante a realização do experimento, o solo foi revolvido mecanicamente, o que favoreceu a mineralização do $\mathrm{N}$ pela decomposição do material vegetal do campo natural que foi incorporada ao solo. Isto também explica o maior teor de $\mathrm{NO}_{3}{ }^{-}$na água de enxurrada no início do ciclo das culturas (teste 1). Este comportamento fica evidente ao relacionar-se o teor de $\mathrm{N}^{-\mathrm{NO}_{3}}{ }^{-}$na água de enxurrada com a quantidade de chuva acumulada, durante o desenvolvimento das culturas (Figura 2). Tanto na cultura de aveia quanto na de ervilhaca, o teor de $\mathrm{N}^{-\mathrm{NO}_{3}}{ }^{-}$diminuiu de forma potencial, com ajuste significativo. Já no quinto teste de chuva (realizado sobre os resíduos culturais), os teores de $\mathrm{N}_{-} \mathrm{NO}_{3}{ }^{-}$na água de enxurrada foram $4,9 \mathrm{e}$ 23,2 vezes maiores do que os do quarto teste, para a aveia e a ervilhaca, respectivamente (Quadro 2). Além disso, na ervilhaca, o teor de $\mathrm{NO}_{3}^{-}$na água de enxurrada do quinto teste foi significativamente superior ao encontrado no início do ciclo da cultura (teste 1). Isso mostra que a ervilhaca possui maior potencial para liberar $\mathrm{N}-\mathrm{NO}_{3}^{-}$do que a aveia na fase inicial de decomposição dos resíduos. $\mathrm{O} \mathrm{N}-\mathrm{NO}_{3}{ }^{-}$é a

Quadro 2. Teor de $\mathrm{N}_{-} \mathrm{NO}_{3}{ }^{-}$solúvel na água de enxurrada nas culturas e nos testes de chuva simulada

\begin{tabular}{|c|c|c|c|c|c|}
\hline \multirow{2}{*}{ Cultura } & \multicolumn{5}{|c|}{ Teste de chuva } \\
\hline & Teste 1 & Teste 2 & Teste 3 & Teste 4 & Teste 5 \\
\hline Aveia & $2,54 \mathrm{a}^{*}$ & $0,30 c^{*}$ & $0,20 c^{\mathrm{ns}}$ & $0,24 c^{\mathrm{ns}}$ & $1,17 b^{*}$ \\
\hline Ervilhaca & $1,95 \mathrm{~b}$ & $0,89 \mathrm{c}$ & $0,24 \mathrm{c}$ & $0,35 \mathrm{c}$ & $4,63 \mathrm{a}$ \\
\hline
\end{tabular}

Média sucedida por mesma letra minúscula na linha, dentro de cada cultura, não difere significativamente pelo teste de Tukey $(\mathrm{p}<0,05)$. Efeito de cultura, dentro de cada teste: ${ }^{*}$ significativo e ${ }^{\text {ns }}$ não-significativo por análise de variância, utilizando-se o teste $\mathrm{F}(\mathrm{p}<0,05)$. Média das formas de semeadura e das repetições. 


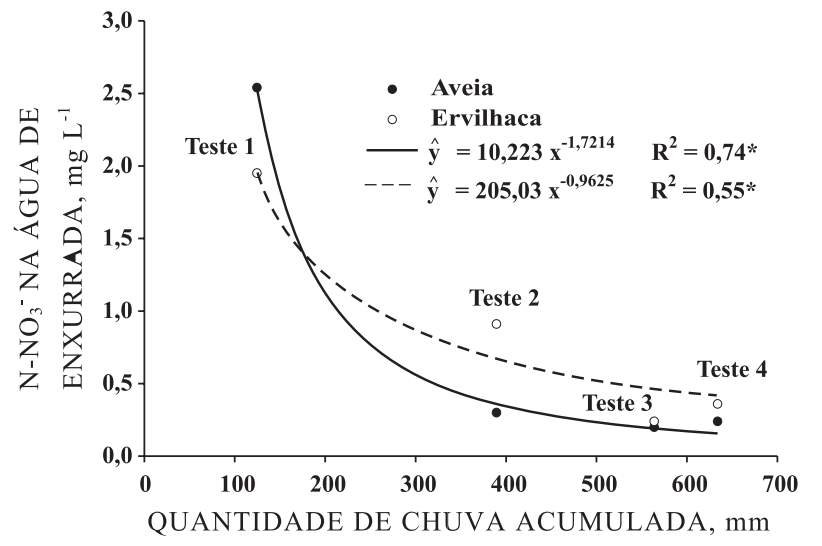

Figura 2. Relação entre o teor de $\mathrm{N}-\mathrm{NO}_{3}{ }^{-}$na água de enxurrada e quantidade de chuva acumulada (natural e simulada) durante o ciclo das culturas de aveia e ervilhaca (média das formas de semeadura e das repetições).

forma de $\mathrm{N}$ mineral predominante no solo, sendo, no último teste, aproximadamente 2,5 vezes maior do que o $\mathrm{N}-\mathrm{NH}_{4}{ }^{+}$, independente do tipo de cultura (Quadros 1 e 2)

Dentro de cada teste de chuva simulada, observase que, no primeiro teste, houve diferença no teor de $\mathrm{N}-\mathrm{NO}_{3}{ }^{-}$na água de enxurrada entre as culturas e entre as formas de semeadura (Quadros 2 e 3). A aveia apresentou teor de $\mathrm{N}-\mathrm{NO}_{3}{ }^{-} 30 \%$ maior do que a ervilhaca, o que se deve à aplicação de $\mathrm{N}$ em cobertura na forma de uréia, imediatamente antes deste teste de chuva. Em relação às formas de semeadura, a realizada em contorno apresentou teor de $\mathrm{N}-\mathrm{NO}_{3}{ }^{-}$ superior à feita a lanço e à pendente (Quadro 3). Isso pode estar relacionado ao seguinte fato: na semeadura em contorno, os sulcos dispostos transversalmente no declive retiveram a água que permaneceu em contato com o solo e com os resíduos do campo natural em decomposição por maior período de tempo do que no caso da semeadura na pendente. Nessa forma de semeadura, os sulcos em direção ao declive facilitaram o rápido escoamento da água que teve menor tempo de contato com o solo e com os resíduos culturais. O maior contato da água com o resíduo vegetal pode ter aumentado o teor de $\mathrm{N}-\mathrm{NO}_{3}{ }^{-}$na água de enxurrada na semeadura realizada em contorno em relação àquela realizada na pendente e a lanço. Na semeadura a lanço, o fato de haver apenas microdepressões decorrentes da rugosidade ao acaso impediu a formação de uma lâmina d'água dentro dessas depressões, diminuindo assim o tempo de contato da água com os resíduos da vegetação original em decomposição. No segundo teste de chuva, houve diferença apenas entre as culturas, e a ervilhaca apresentou teor de $\mathrm{N}-\mathrm{NO}_{3}{ }^{-}$ na água de enxurrada três vezes superior à aveia (Quadro 2). O maior teor de $\mathrm{N}_{-} \mathrm{NO}_{3}{ }^{-}$na enxurrada proveniente da área com ervilhaca provavelmente ocorreu pelo fato de essa cultura, por ser leguminosa e simbionte, com bactérias fixadoras do $\mathrm{N}_{2}$ atmosférico, ter absorvido menos o elemento do solo em relação à cultura de aveia. Conforme Aita et al. (2004), a maior parte do $\mathrm{N}$ absorvido pela ervilhaca é proveniente da fixação biológica. No mesmo trabalho, os autores observaram que a fixação biológica era responsável por $78 \%$ do $\mathrm{N}$ contido na ervilhaca. Portanto, o elemento em maior quantidade no solo tornou-se mais concentrado na água de escoamento superficial na ervilhaca do que na aveia. Neste teste de chuva, não houve diferença significativa entre as formas de semeadura, possivelmente pelo fato de os resíduos do campo natural já estarem decompostos. No estádio de florescimento das culturas (testes três e quatro), o teor de $\mathrm{N}-\mathrm{NO}_{3}{ }^{-}$na água de enxurrada foi baixo e não diferiu entre as culturas ou entre as formas de semeadura (Quadros 2 e 3). Isso confirma o fato de os maiores teores de $\mathrm{N}$ perdidos na enxurrada ocorrerem no início do ciclo das culturas e não na fase final de crescimento vegetal, concordando com Bertol et al. (2003). No teste de chuva realizado sobre os resíduos culturais (teste 5), o teor de $\mathrm{N}_{-} \mathrm{NO}_{3}^{-}$foi influenciado pelas culturas e formas de semeadura. $\mathrm{O}$ teor de $\mathrm{N}-\mathrm{NO}_{3}{ }^{-}$foi aproximadamente quatro vezes maior sobre os resíduos de ervilhaca do que de aveia (Quadro 2), sendo este comportamento já discutido anteriormente. Comparando as formas de semeadura, aquela realizada em contorno diferiu estatisticamente

Quadro 3. Teor de $\mathrm{N}_{-} \mathrm{NO}_{3}{ }^{-}$solúvel na água de enxurrada nas formas de semeadura e nos testes de chuva simulada

\begin{tabular}{cccc}
\hline & & \multicolumn{2}{c}{ Forma de semeadura } \\
\cline { 2 - 3 } Teste de chuva & Pendente & Lanço & Contorno \\
Teste 1 & $1,31 \mathrm{~b}$ & $1,63 \mathrm{~b}$ & $3,79 \mathrm{a}$ \\
Teste 2 & $0,58 \mathrm{a}$ & $0,41 \mathrm{a}$ & $0,80 \mathrm{a}$ \\
Teste 3 & $0,25 \mathrm{a}$ & $0,14 \mathrm{a}$ & $0,27 \mathrm{a}$ \\
Teste 4 & $0,23 \mathrm{a}$ & $0,24 \mathrm{a}$ & $0,41 \mathrm{a}$ \\
Teste 5 & $2,84 \mathrm{~b}$ & $2,27 \mathrm{~b}$ & $3,61 \mathrm{a}$
\end{tabular}

Média sucedida por mesma letra minúscula na linha, dentro de cada teste, não difere significativamente pelo teste de Tukey $(\mathrm{p}<0,05)$. Média das culturas e das repetições. 
das demais, apresentando teor de $\mathrm{N}-\mathrm{NO}_{3}{ }_{3}^{-}$na água de enxurrada $41 \%$ superior ao da média das formas de semeadura a lanço e pendente (Quadro 3). Este comportamento assemelha-se ao ocorrido no primeiro teste de chuva. Nesse caso, como os resíduos culturais foram deitados na superfície do solo após as culturas terem sido roçadas, eles ficaram em contato com a água da chuva que estava acumulada dentro dos sulcos dispostos no sentido contrário ao declive, podendo, com isso, ter aumentado o teor de $\mathrm{N}^{-} \mathrm{NO}_{3}{ }^{-}$ na água de enxurrada em relação às demais formas de semeadura.

Os teores de $\mathrm{N}^{-\mathrm{NO}_{3}}{ }^{-}$na água de enxurrada ficaram abaixo do valor referenciado pela resolução Brasil - CONAMA (2005), em todos os testes de chuva. Esta resolução estabelece padrões de qualidade das águas e, de acordo com ela, o teor de $\mathrm{N}^{-} \mathrm{NO}_{3}{ }^{-}$para água doce não deve ser superior a $10 \mathrm{mg} \mathrm{L}^{-1}$. Este comportamento ocorreu possivelmente porque parte do $\mathrm{N}-\mathrm{NO}_{3}{ }^{-}$lixiviou no perfil do solo e, consequentemente, menor foi o seu teor na água de enxurrada.

\section{Relação de $\mathrm{N}$ na água de enxurrada com $\mathrm{N}$ na camada de 0-2,5 cm do solo}

Relacionando o teor de $\mathrm{N}-\mathrm{NH}_{4}{ }^{+}+\mathrm{N}-\mathrm{NO}_{3}{ }^{-}$solúvel na água de enxurrada com o teor de $\mathrm{N}$ mineral $(\mathrm{N}$ $\left.\mathrm{NH}_{4}^{+}+\mathrm{N}-\mathrm{NO}_{3}{ }^{-}\right)$na camada de $0-2,5 \mathrm{~cm}$ do solo, obteve-se uma correlação positiva do tipo potencial, com ajuste significativo (Figura 3). Isso mostra que maiores teores desse nutriente na camada superficial do solo tendem a elevar os teores na água de enxurrada, já que essa camada interage com a água de enxurrada e é a camada preferencialmente removida no processo erosivo. Nesse caso, $81 \%$ do $\mathrm{N}$ solúvel na água de enxurrada foi explicado pelo $\mathrm{N}$ mineral da camada superficial do solo.

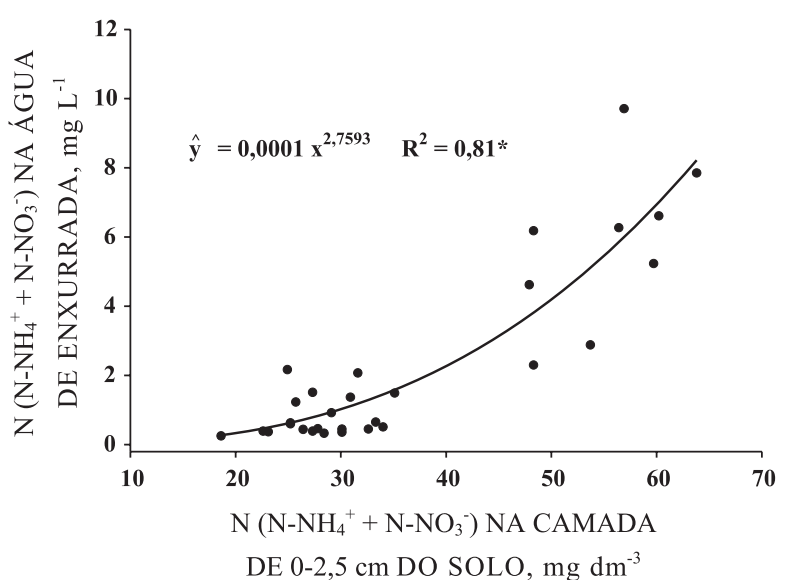

Figura 3. Relação entre o teor de $\mathrm{N}$ na água de enxurrada e o teor de $\mathrm{N}$ na camada de $0-2,5 \mathrm{~cm}$ do solo, nos tratamentos, nas culturas e nos testes de chuva simulada (média das repetições).

\section{CONCLUSÕES}

1. A aplicação de $\mathrm{N}$ em cobertura na aveia, na forma de uréia, imediatamente antes da chuva, aumentou o teor de $\mathrm{N}_{-} \mathrm{NH}_{4}{ }^{+}$na água de enxurrada, apresentando risco potencial em prejudicar a comunidade aquática.

2. Na água de enxurrada, o teor de $\mathrm{N}^{-\mathrm{NO}_{3}}{ }^{-}$foi maior na semeadura realizada em contorno ao declive do que nas semeaduras a lanço e pendente quando havia resíduos vegetais em decomposição na superfície do solo.

3. Os teores de $\mathrm{N}-\mathrm{NH}_{4}{ }^{+}$e $\mathrm{N}-\mathrm{NO}_{3}{ }^{-}$na água de enxurrada foram maiores no início do que no fim do ciclo das culturas de aveia e ervilhaca.

4. Os teores de $\mathrm{N}-\mathrm{NH}_{4}{ }^{+}$e $\mathrm{N}-\mathrm{NO}_{3}{ }^{-}$na água de enxurrada foram maiores quando provenientes de área com resíduos de ervilhaca mantidos na superfície do solo do que com resíduos de aveia.

5. Os teores de $\mathrm{N}^{-\mathrm{NH}_{4}}{ }^{+}$e $\mathrm{N}-\mathrm{NO}_{3}{ }^{-}$na água de enxurrada foram $81 \%$ explicados pelos teores de $\mathrm{N}$ mineral contidos na camada de $0-2,5 \mathrm{~cm}$ do solo, por meio de modelo potencial crescente.

\section{LITERATURA CITADA}

AITA, C. \& GIACOMINI, S.J. Decomposição e liberação de nitrogênio de resíduos culturais de plantas de cobertura de solo solteiras e consorciadas. R. Bras. Ci. Solo, 27:601612, 2003

AITA, C.; URQUIAGA, S.; ALVES, B.J.R.; BODDEY, R.M.; JANTALIA, C.P. \& GIACOMINI, S.J. Estimativa da fixação biológica de $\mathrm{N}$ em leguminosas para adubação verde usando variações na abundância natural em ${ }^{15} \mathrm{~N}$. In: FERTBIO-2004, Lages. Resumo expandido. Lages, Sociedade Brasileira de Ciência do Solo, 2004. CD-ROM.

ALBERTS, E.E.; SCHUMAN, G.E. \& BURWELL, R.E. Seasonal runoff losses of nitrogen and phosphorus form Missouri Valley los watersheds. J. Environ. Qual., 7:203207, 1978.

BARBOSA, F.T. Erosão hídrica em três formas de semeadura de aveia e ervilhaca em um Cambissolo Húmico: Perdas de nutrientes e carbono orgânico. Lages, Universidade do Estado de Santa Catarina, 2008.73p. (Tese de Mestrado)

BERTOL, I.; COGO, N.P. \& LEVIEN, R. Relações da erosão hídrica com métodos de preparo do solo, na ausência e na presença de cobertura por resíduo cultural de trigo. R. Bras. Ci. Solo, 11:187-192, 1987.

BERTOL, I.; MELLO, E.L.; GUADAGNIN, J.C.; ZAPAROLLI, A.L.V. \& CARRAFA, M.R. Sci. Agron., 60:581-586, 2003.

BERTOL, I.; LEITE, D.; GUADAGNIN, J.C. \& RITTER, S.R. Erosão hídrica em um Nitossolo Háplico submetido a diferentes sistemas de manejo sob chuva simulada. II Perdas de nutrientes e carbono orgânico. R. Bras. Ci. Solo, 28:485-494, 2004. 
BERTONI, J. \& LOMBARDI NETO, F. Conservação do solo. 5.ed. São Paulo: Ícone, 2005. 355p.

BREMNER, J.M. \& KEENEY, D.S. Determination and isotope ratio analysis of different forms of nitrogen is soils: 3 . Exchangeable ammonium, nitrate e nitrite by extraction - distillation methods. Soil Sci. Soc. Am. Proc., 30:577$582,1966$.

CANTARELLA, H. Nitrogênio. In: NOVAIS, R.F.; ALVAREZ V., V.H.; BARROS, N.F.; FONTES, R.L.F.; CANTARUTTI, R.B. \& NEVES, J.C.L. Fertilidade do solo. Viçosa, MG, Sociedade Brasileira de Ciência do Solo, 2007. p.375-470.

CONSELHO NACIONAL DO MEIO AMBIENTE - CONAMA. Resolução n. 357 de 17 de março de 2005. Dispõe sobre a classificação dos corpos de água e diretrizes ambientais para o seu enquadramento, bem como estabelece condições e padrões de lançamento de efluentes e dá outras providências. Diário oficial da União. Brasília, 2005.

COMISSÃO DE FERTILIDADE DO SOLO - SBCS. Manual de adubação e calagem para os Estados do Rio Grande do Sul e Santa Catarina. Passo Fundo, 2004. 400p.

LEITE, D. Erosão hídrica sob chuva simulada em um Nitossolo Háplico submetido a diferentes manejos. Lages, Universidade do Estado de Santa Catarina, 2003. 100p. (Tese de Mestrado)

LUCIANO, R.V. Erosão hídrica em três formas de semeadura de aveia e ervilhaca em um Cambissolo Húmico. Lages, Universidade do Estado de Santa Catarina, 2008. 84p. (Tese de Mestrado)
McISAAC, G.F.; MITCHELL, J.K. \& HIRSCHI, M.C. Dissolved phosphorus concentrations in runoff from simulated rainfall on corn and soybean tillage systems. J. Soil Water Consev., 50:383-387, 1995.

PIRES, F.R. \& SOUZA, C.M. Práticas mecânicas de conservação do solo e da água. Viçosa, MG, Universidade Federal de Viçosa, 2003. 176p.

POTE, D.H.; DANIEL, T.C.; MOORE, P.A.; NICHOLS, D.J.; SHARPLEY, A.N. \& EDWARS, D.R. Relating extractable soil phosphorus to phosphorus losses in runoff. Soil Sci. Soc. Am. J., 60:855-859, 1996.

SCHICK, J.; BERTOL, I.; BALBINOT JR, A.A. \& BATISTELA, O. Erosão hídrica em Cambissolo Húmico alumínico submetido a diferentes sistemas de preparo e cultivo do solo: II. Perdas de nutrientes e carbono orgânico. R. Bras. Ci. Solo, 24:437-447, 2000.

SEGANFREDO, M.L.; ELTZ, F.L.F. \& BRUM, A.C.R. Perdas de solo, água e nutrientes por erosão em sistemas de culturas em plantio direto. R. Bras. Ci. Solo, 21:287-291, 1997.

SHARPLEY, A.N.; SMITH, S.J. \& NANEY, J.W. Environmental impact of agricultural nitrogen and phosphorus use. American Chemical Society, 1987. 11p.

SWANSON, N.P. Suggestions for use of the rotating-boom field plot rainfall simulator to obtain data for application of the soil loss equation. Entre-Rios, FAO, 1975. 65p. (Report of FAO Consultant) 